\title{
Maintenance of Certification: A message from the American Board of Thoracic Surgery (ABTS)
}

William A. Gay, Jr, MD

Executive Director, the American Board of Thoracic Surgery, Chicago, Ill.

Published simultaneously in J Thorac Cardiovasc Surg 2005;130:5-6 and Ann Thorac Surg 2005;80:1-2

Received for publication Feb 25, 2005; accepted for publication March 1, 2005.

Address for reprints: William A. Gay, Jr, MD, Department of Surgery, Washington University School of Medicine, Queeny Tower, Suite 3108, 1 Barnes-Jewish Hospital Plaza, St Louis, MO 63110 (E-mail: gayw@msnotes.wustl.edu).

J Thorac Cardiovasc Surg 2005;130:5-6

$0022-5223 / \$ 30.00$

Copyright $\odot 2005$ by The American Association for Thoracic Surgery and The Society of Thoracic Surgeons

doi:10.1016/j.jtcvs.2005.03.002
$\mathrm{S}$ ince 1976, all certificates issued by the ABTS have been valid for 10 years, after which time diplomates have been required to "recertify." It is gratifying that the recertification rate among ABTS diplomates has been nearly $100 \%$ over the years, many having recertified more than once. The recertification process of the ABTS, like that of many of the other American Board of Medical Specialties (ABMS) boards, has focused largely on assuring that the diplomate is, indeed, practicing the specialty, is appropriately licensed, and has participated in relevant continuing medical education, including participating in a standard self-assessment exercise (SESATS). In recent years considerable enthusiasm has arisen to elevate the recertification process in an effort to assure the public that board-certified specialists have remained current with evolving knowledge and technology, that their practices meet acceptable standards, and that they are recognized and respected as specialists by their patients and peers. It is in this setting that Maintenance of Certification (MOC) has evolved.

As one of the 24 member boards of the ABMS, the ABTS is required to develop a process for MOC that meets the standards set for all boards. This process, as it is envisioned by the ABTS, is outlined in the paragraphs that follow. Successful implementation will require the enthusiastic participation of all diplomates, thoracic surgery residents, the Residency Review Committee for Thoracic Surgery (RRC-TS), the Thoracic Surgery Directors Association (TSDA), both of the thoracic surgery journals, and the national and regional societies. The ABTS seeks comments and suggestions from all regarding this process. Please address your comments to me at the ABTS by either regular mail (633 North Saint Clair Street, Suite 2320, Chicago, IL 60611) or E-mail (info@abts.org). Additional information regarding MOC will be placed on the ABTS Web site (www.abts.org) and/or in the journals at regular intervals.

\section{What Is MOC?}

"A comprehensive process ... based on quality standards set by member boards and other standard-setting organizations ... focusing on the continuous process of assessment and improvement of a physician over the course of his/her career." (ABMS Press Release, November 11, 2004.)

\section{What Are the Options for the ABTS?}

Dr Gordon Olinger, immediate past Examination Chair of the ABTS, answered this question as follows:

1. "Accept the status quo, assuming that the present program adequately addresses the issue.

2. Audit practice performance, pitting one physician's performance against another's.

3. Change to a program documenting participation in a valid process of assessment and improvement in quality of care as measured against evidence-based standards." (G. N. Olinger, ABMS White Paper, February 26, 2003.)

The ABTS feels that the third approach is the most appropriate.

The member boards of the ABMS have identified four components for MOC programs, and the ABTS has developed methods for documenting that our diplomates have fulfilled these requirements. 


\section{Professional Standing}

This is essentially unchanged from the present requirements for recertification. Diplomates must hold a currently valid, full and unrestricted license to practice medicine in every jurisdiction (state, territory, province, etc) in which he/she practices. If restrictions existed previously, a letter from the relevant agency documenting removal of all restrictions is required. Diplomates must hold privileges to practice thoracic surgery in a hospital(s) accredited by the Joint Commission on Accreditation of Healthcare Organizations (JCAHO) or other institutions judged acceptable by the Board (with letter of attestation from the chief of surgical services at the diplomate's principal hospital).

\section{Lifelong Learning and Self-Assessment}

Diplomates must complete 200 hours of Category I continuing medical education (CME) in the broad category of cardiothoracic surgery over each 5-year period (an average of 40 hours per year). Unless approved in advance by the Accreditation Council for Continuing Medical Education (ACCME), industry-sponsored "training" sessions do not qualify. The annual meetings of the national (The American Association for Thoracic Surgery and The Society of Thoracic Surgeons) and regional (Southern Thoracic Surgical Association [STSA] and The Western Thoracic Surgical Association [WTSA]) thoracic surgery organizations and the Clinical Congress of the American College of Surgeon do qualify so long as the activity has ACCME approval. New modalities to facilitate CME are being developed that will make it easier to acquire the required hours (journalbased, e-learning modules, national/regional society meetings on the Internet, etc.). Morbidity/mortality conferences may account for no more than 12 hours of CME credit per year. In addition, each diplomate must complete the SESATS exercise 5 years after initial certification and every 10 years thereafter.

\section{Cognitive Expertise}

Once during each 10-year MOC cycle, the diplomate must take, and pass, a secure, comprehensive written examination that will test fundamental and practice-related knowledge. Since an individual's practice may be in only one or two of the recognized areas of thoracic surgery (adult cardiac, general thoracic, or pediatric cardiac), either the examination itself or the grading of the test will be weighted toward that area. Aggregate results of the examination will be available to the public on the ABTS Web site.

\section{Evaluation of Performance in Practice}

The following points state the goals of the ABTS regarding practice evaluation and how the Board intends to achieve them.

A. Reference letters. Letters of reference on behalf of the diplomate documenting licensing, hospital privileges, level of clinical activity, and stature within the surgical community will be solicited from responsible members of the staff of the diplomate's principal hospital (Chief of Surgery, Chief of Staff, Chair of Credentials Committee, Division Chief, etc). These letters will address such issues as general medical knowledge, surgical judgment, technical skill, moral and ethical qualities, communication and interpersonal skills, evidence of substance abuse, and/or any disciplinary actions. Such letters will be solicited at 5-year intervals using names provided by the diplomate.

B. Peer (and patient) evaluation. Once during each 10-year MOC cycle each diplomate will be required to submit the names of at least four physicians familiar with his/her practice who may serve as peer evaluators. At least half of these physicians must have referred patients to the diplomate, and no more than one may be a practice partner. Methods for patient input into the physician evaluation process are being developed.

C. Outcome data. Diplomates must keep a record of a representative sample (at least their five most frequently done procedures) for documentation of clinical activity and outcomes. The diplomate is expected to compare his/her outcomes to national norms and use this information as a means of practice improvement. Participation in one or more of the recognized data banks that track outcome information (STS Databank, Northern New England Databank, Virginia Cardiac Surgery Initiative, etc) is strongly encouraged, but the maintenance of a "local" op log could also satisfy this requirement. Additional tools are also being developed to make this process easier for the practicing surgeon.

Many of the requirements for MOC are already in place as requirements for recertification. The ABTS recognizes that the activities described above may impose additional effort and, possibly, expense to our diplomates. It is our goal that, working closely with the other organizations in thoracic surgery, the MOC process, once implemented, will be both effort and expense neutral when compared with today's recertification process. Although no specific timeline has been set, the ABTS would like to complete the planning phase during calendar year 2005 and be prepared for implementation in 2006. YOUR COMMENTS AND SUGGESTIONS ARE VERY IMPORTANT! 